\title{
Brief communication: Rapid assessment of damaged residential buildings in the Florida Keys after Hurricane Irma
}

\author{
Siyuan Xian ${ }^{1}$, Kairui Feng ${ }^{1}$, Ning Lin ${ }^{1}$, Reza Marsooli ${ }^{1}$, Daniel Chavas ${ }^{2}$, Jie Chen $^{2}$, and Adam Hatzikyriakou ${ }^{1}$ \\ ${ }^{1}$ Department of Civil and Environmental Engineering, Princeton University, Princeton, USA \\ ${ }^{2}$ Department of Earth, Atmospheric, and Planetary Sciences, Purdue University, West Lafayette, USA
}

Correspondence: Siyuan Xian (sxian@princeton.edu)

Received: 12 January 2018 - Discussion started: 29 January 2018

Accepted: 23 June 2018 - Published: 27 July 2018

\begin{abstract}
On 10 September 2017, Hurricane Irma made landfall in the Florida Keys and caused significant damage. Informed by hydrodynamic storm surge and wave modeling and post-storm satellite imagery, a rapid damage survey was soon conducted for $1600+$ residential buildings in Big Pine Key and Marathon. Damage categorizations and statistical analysis reveal distinct factors governing damage at these two locations. The distance from the coast is significant for the damage in Big Pine Key, as severely damaged buildings were located near narrow waterways connected to the ocean. Building type and size are critical in Marathon, highlighted by the near-complete destruction of trailer communities there. These observations raise issues of affordability and equity that need consideration in damage recovery and rebuilding for resilience.
\end{abstract}

\section{Introduction}

Hurricane Irma made landfall near Cudjoe Key (lower Florida Keys) on 10 September 2017, as a Category 3 storm. Irma caused widespread damage to the Florida Keys due to storm surge and waves. Informed by hydrodynamic modeling and post-storm satellite imagery, we carried out a field survey soon after the event (21-24 September) to investigate the damage to the Keys, particularly the Big Pine Key and Marathon areas.

Post-hurricane damage studies have improved our understanding of coastal vulnerability (e.g., Xian et al., 2015, and Hatzikyriakou et al., 2015 for Hurricane Sandy; van de Lindt et al., 2007, for Hurricane Katrina). Here, we conduct a damage survey and assessment for Hurricane Irma, and we use a statistical regression approach to quantify the contribution of various hazard and vulnerability factors to the damage. Such post-event assessments can provide crucial information for implementing post-storm response measures (Lin et al., 2014; Horner and Wildener, 2011; Al-Kanj et al., 2016) and for developing vulnerability models (e.g., USACE, 2015; Hatzikyriakou and Lin, 2017). The raw and analyzed data from this study appear on DesignSafe ${ }^{1}$, a web-based research platform of the National Science Foundation's (NSF) Natural Hazards Engineering Research Infrastructure (NHERI).

\section{Storm surge and wave simulation}

To understand the hazard and inform the field survey, we first use the coupled hydrodynamic and wave model ADCIRC + SWAN (Dietrich et al., 2012; Marsooli and Lin, 2018) to simulate the storm tide (i.e., water level) and wave height for Hurricane Irma. To simulate Irma's storm tide and wave (Fig. 1), we apply the surface wind (at $10 \mathrm{~m}$ ) and sealevel pressure fields from National Centers for Environmental Prediction Final (NCEP FNL) operational global analysis data $\left(0.25^{\circ} \times 0.25^{\circ} \times 6 \mathrm{~h}\right)$. The model results, e.g., the time series in Fig. 1, indicate that the model satisfactorily captures the temporal evolution and the peak values of the water levels and wave heights induced by Hurricane Irma. The model results show that the highest water levels, between 2 and $2.5 \mathrm{~m}$, occurred in southern and southwestern Florida. However, coastal zones in this region are predominantly uninhabited and covered by wetlands, so little loss of life or

\footnotetext{
${ }^{1}$ https://www.designsafe-ci.org/T1\textbackslash\#research, last access:

16 July 2018
} 
(a)

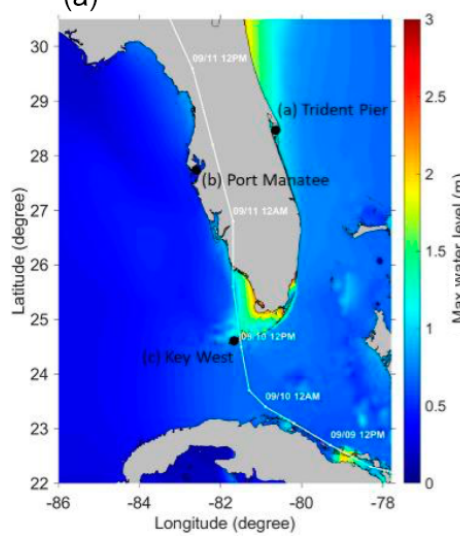

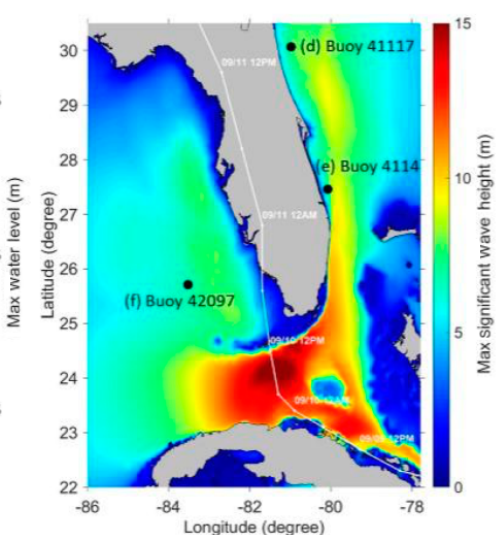

(b)

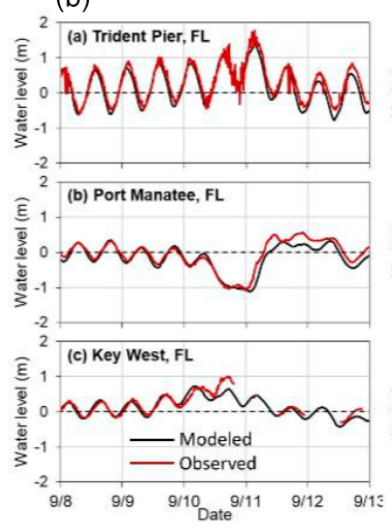

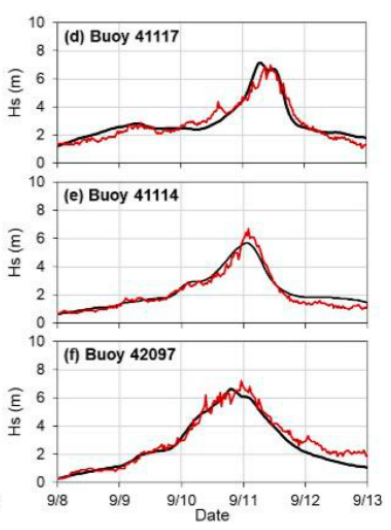

Figure 1. Hydrodynamic modeling of water level and wave height for Hurricane Irma. Panel (a) shows spatial distribution of modeled maximum water level and significant wave height, respectively. White curve represents storm track. Black points show locations of available tidal gauge and buoy stations. Red point indicates approximate location of study area. Panel (b) compares observed and modeled time series of water level and significant wave height $\left(H_{\mathrm{s}}\right)$, respectively.
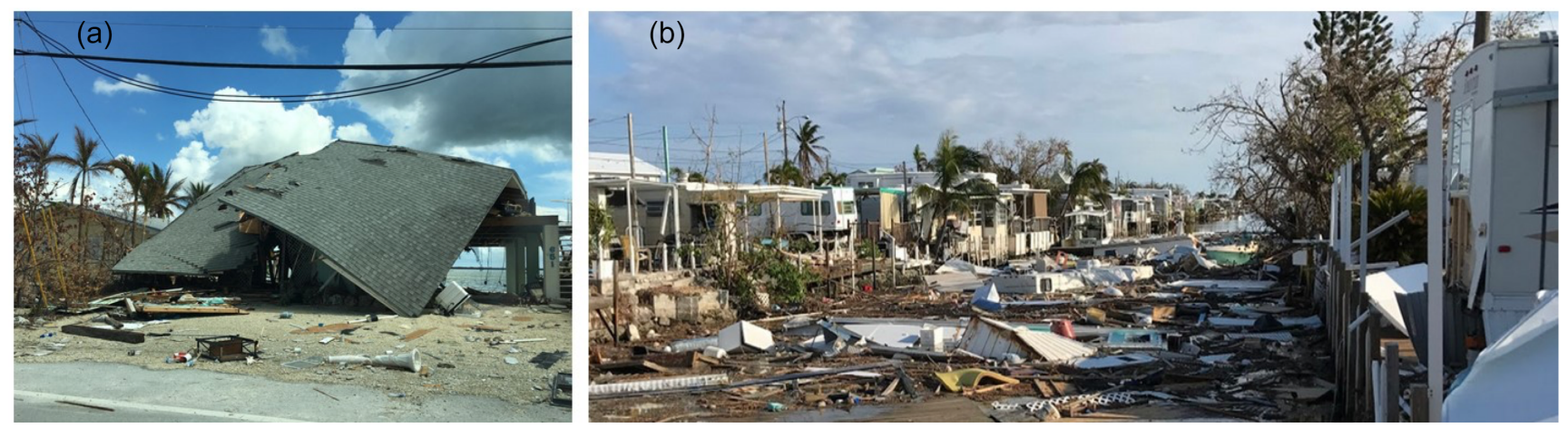

Figure 2. Photos of damage in (a) Big Pine Key: storm surge damage beside a waterway (left side of building) and (b) Marathon: trailer community with house debris filling a waterway.

Table 1. The number of buildings assigned into each damage state category.

\begin{tabular}{lrr}
\hline & Marathon & Big Pine Key \\
\hline No damage (green) & 336 & 253 \\
Minor damage (yellow) & 273 & 362 \\
Major damage (orange) & 65 & 113 \\
Destroyed (red) & 137 & 118 \\
\hline
\end{tabular}

property is expected. High water levels are also estimated for the Florida Keys, especially islands located on the right side of the storm track. For example, the peak storm tide in Big Pine Key and Marathon reaches up to $2 \mathrm{~m}$. The model results also show that large waves with a significant wave height of about $14 \mathrm{~m}$ reached a few kilometers off the Florida Keys. In contrast, wave heights off the southern and southwestern coasts of Florida are estimated to be small $(<2 \mathrm{~m})$.

\section{Damage survey and analysis}

NOAA's post-storm satellite imagery ${ }^{2}$ provides an overview of Irma's impact. This imagery was acquired by the NOAA Remote Sensing Division. The approximate ground sample distance (GSD) for each pixel is $50 \mathrm{~cm} / \mathrm{zoom}$ level 18 . The two selected survey areas in Florida Keys, the Big Pine Key and Marathon, suffered the most severe damage, according to the satellite imagery, and experienced high water levels and wave heights, indicated by the hydrodynamic modeling.

Field surveys can provide detailed information for analyzing damage mechanisms. However, traditional on-site surveys require a significant time and effort, as surveyors must walk through affected areas and photograph damaged properties. Thus, we applied a rapid survey method. Rather than walking, we drove at a speed of $16 \mathrm{~km} \mathrm{~h}^{-1}$ throughout the affected areas, taking GPS-informed pictures from the rare

\footnotetext{
${ }^{2}$ https://storms.ngs.noaa.gov/storms/irma/index.html\T1। textbackslash\#6/28.139/-81.547, last access: 16 July 2018
} 

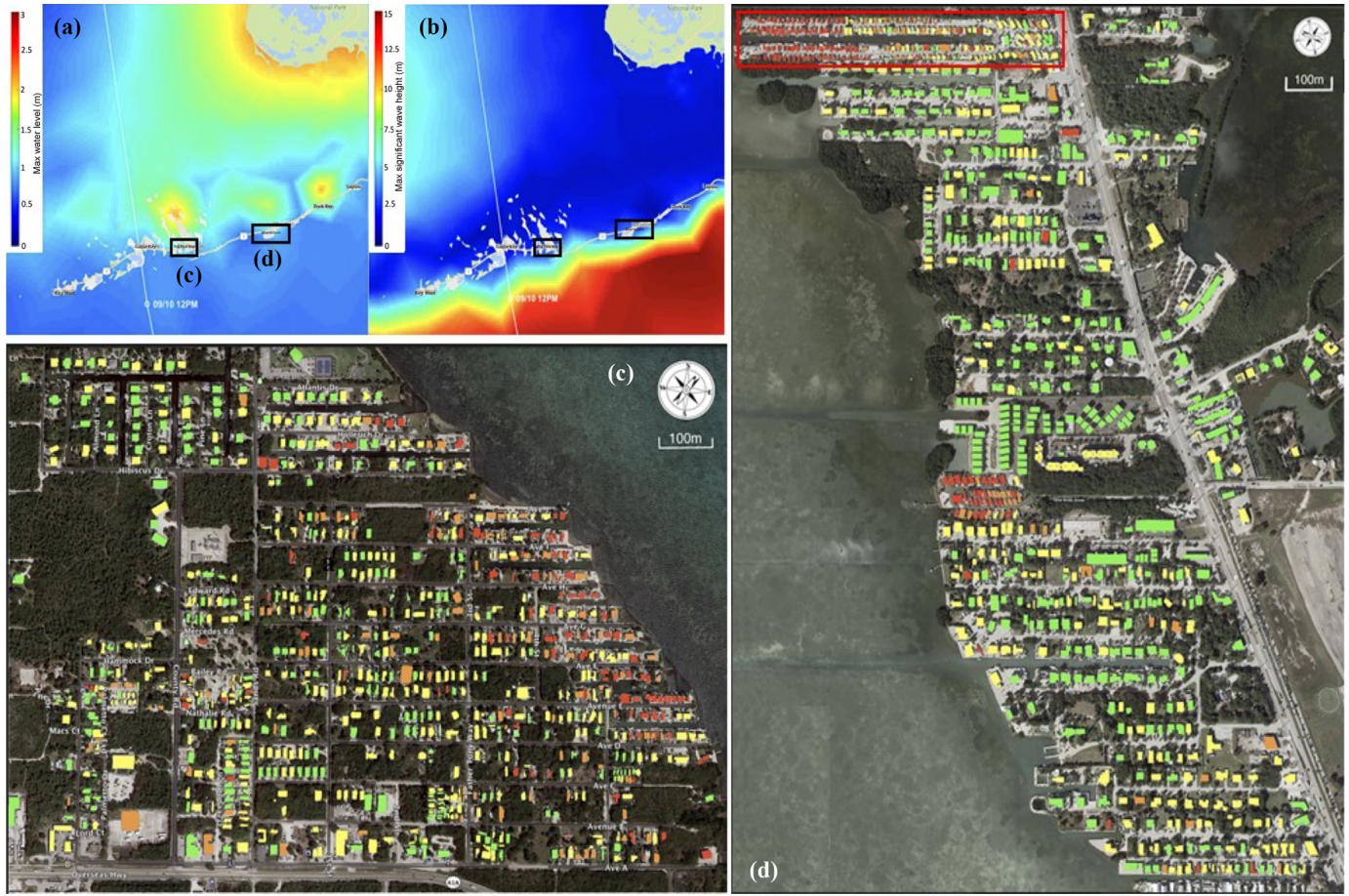

Figure 3. Spatial distribution of estimated hazards and damage states in study areas. Panels (a) and (b) show simulated maximum total water level and significant wave height, respectively; panels (c) and (d) show assessed damage state (none: green; minor: yellow; major: orange; destroyed: red) for residential buildings in Big Pine Key and Marathon, respectively.

Table 2. Ordered logistic regression models that correlate damage state with vulnerability factors (a) for 846 assessed buildings in Big Pine Key (219 trailers and 627 single family); (b) for 811 buildings in Marathon (263 trailers and 548 single family).

\begin{tabular}{lrrrrr}
\hline (a) Factors in damage state & Coef. & SE & $z$ & $p$ value & $95 \%$ conf. interval \\
\hline House type & 0.0233 & 1.987 & 0.12 & 0.906 & $(-0.366-0.413)$ \\
House size (square meters) & -0.00081 & 0.00059 & -1.36 & 0.174 & $(-0.0198-0.000358)$ \\
Distance to coast (meters) & 0.00718 & 0.00069 & 10.42 & 0.000 & $(0.00583-0.00853)$ \\
\hline (b) Factors in damage state & Coef. & SE & $z$ & $p$ value & $95 \%$ conf. interval \\
\hline House type & -1.64 & 0.207 & -7.92 & 0.000 & $(-2.05$ to -1.236$)$ \\
House size (square meters) & -0.04961 & 0.001 & -4.88 & 0.000 & $(-0.069$ to -0.0029$)$ \\
Distance to coast (meters) & -0.0002145 & 0.00058 & -0.37 & 0.713 & $(-0.0136-0.00093)$ \\
\hline
\end{tabular}

side windows. Over two days, the team took $3700+$ pictures for $1600+$ residential buildings comprised of single family and mobile homes (e.g., trailers).

Using the collected photos and satellite images, we categorize the damage state for each surveyed residential building. Satellite images are primarily used to assess roof damage. More detailed damage mechanisms are further evaluated from the photos. We adopt FEMA's damage state criteria used in the damage assessment study for Hurricane Sandy ${ }^{3}$. The categories include no or very limited damage, minor damage, major damage, and destroyed.

\footnotetext{
${ }^{3}$ https://www.arcgis.com/home/item.html?id= 307dd522499d4a44a33d7296a5da5ea0, last access: 16 July 2018
}

We find that the destroyed and severely damaged buildings were caused largely by hydrodynamic forces induced by storm surge and waves. For example, Fig. 2a shows that storm surge and waves completely crashed the lower part of a building in Big Pine Key. Figure $2 b$ shows debris from damaged trailers floating in the water in a trailer community in Marathon. Although direct observation of the surge and wave heights are not available at the two sites, the observed storm surge damage is consistent with the high surge and wave heights estimated by the hydrodynamic modeling (Fig. 3a and b). The assessed damage state for each building appears in Fig. $3 \mathrm{c}$ and $\mathrm{d}$. The number of buildings assigned into each category is shown in Table 1 . The slightly 
and moderately damaged buildings (including limited, minor, and major damage states) are 72.7 and $75 \%$ of the total surveyed building for the assessed areas in Big Pine Key and Marathon, respectively. The percentages of the destroyed buildings are 13.9 and $16.9 \%$, respectively. In both areas, the destroyed buildings are clustered. The destroyed buildings in Big Pine Key are near the coastline and narrow waterways, a strong indication that the damage was caused mainly by hydrodynamic forces. The completely destroyed buildings in Marathon cluster in the north and middle parts of the study area. The majority of those buildings are mobile homes.

Statistical analysis confirms these general observations. We use an ordered logistic regression model to correlate the damage state with the following factors: distance from the coastline $(\mathrm{m})$, building type, and building size $\left(\mathrm{m}^{2}\right)$. Distance from the coastline is not correlated with building type or size in both locations $(<0.3)$. The correlation coefficient of building type and size, however, is 0.66 in Big Pine Key and 0.68 in Marathon. Our analysis for Big Pine Key shows that the distance from the coastline is the single significant predictor of damage state ( $p$ value $<0.001$; Table $2 \mathrm{a}$ ), as the damage is dominated by buildings located near narrow waterways connected to the ocean. For Marathon, although many damaged buildings are near the coast, building type and size are the two most significant (although correlated) predictors ( $p$ value $<0.001$; Table $2 \mathrm{~b}$ ), highlighting the near-complete destruction of trailers (which are often small).

Possible measures to reduce flood vulnerability in the study areas include elevating and strengthening the buildings (especially mobile homes) and relocating homeowners living near the coastline (and narrow waterways) further inland (Xian et al., 2017). However, potential financial challenges exist, especially for Marathon, where the median annual income is USD 50976 vs. USD 63716 for Big Pine $\mathrm{Key}^{4}$. Some local homeowners in a destroyed trailer community in Marathon (indicated by the red rectangle in Fig. 3d) with whom we talked had lived in trailers as their primary homes for decades without flood insurance. Financial constraints may hinder their rebuilding or relocating to somewhere safer. As low-income people living in mobile homes suffered most, natural hazards worsen economic inequality in this case. In contrast, discussion with local residents in Big Pine Key indicated that structures there were mostly secondary homes with two or three stories, and many were designed to withstand hurricane hazards (e.g., key assets raised above the ground floor). These observation raise again issues of affordability and equity (Montgomery and Chakraborty, 2015). Policies relevant to hurricane damage recovery and rebuilding must address these issues.

Future studies right following this work would focus on the development of vulnerability/fragility models, which can be used for flood risk management. This development

\footnotetext{
${ }^{4}$ Data come from https://www.point2homes.com/US/ Neighborhood/FL.html, last access: 16 July 2018
}

requires more accurate flood hazard estimation based on higher-resolution hydrodynamic and inundation modeling (Hatzikyriakou and Lin, 2017). In addition, the damage data can be combined with socio-economic data to better understand the overall impact of Hurricane Irma.

Data availability. The data can be accessed from the following webpage: https:/github.com/KelvinFkr2015/ Rapid-Risk-Assessment-for-Irma-Data (last access: 23 July 2018).

Competing interests. The authors declare that they have no conflict of interest.

Acknowledgements. This study is supported by NSF grant CMMI1652448 .

Edited by: Jean-Philippe Malet

Reviewed by: two anonymous referees

\section{References}

Al-Kanj, L., Powell, W. B., and Bouzaiene-Ayari, B.: The Information-Collecting Vehicle Routing Problem: Stochastic Optimization for Emergency Storm Response, arXiv preprint arXiv:1605.05711, 2016.

Dietrich, J. C., Tanaka, S., Westerink, J. J., Dawson, C. N., Luettich Jr., R. A., Zijlema, M., Holthuijsen, L. H., Smith, J. M., Westerink, L. G., and Westerink, H. J.: 'Performance of the Unstructured-Mesh, SWAN+ADCIRC Model in Computing Hurricane Waves and Surge, J. Sci. Comput., 52, Springer US, 468-497, https://doi.org/10.1007/s10915-011-9555-6, 2012.

Hatzikyriakou, A., Lin, N., Gong, J., Xian, S., Hu, X., and Kennedy, A.: Component-based vulnerability analysis for residential structures subjected to storm surge impact from Hurricane Sandy, Nat. Hazards Rev., 17, 05015005, https://doi.org/10.1061/(ASCE)NH.1527-6996.0000205, 2015.

Hatzikyriakou, A. and Lin, N.: Simulating Storm Surge Waves for Structural Vulnerability Estimation and Flood Hazard Mapping, Nat. Hazards, 344 1-24, https://doi.org/10.1007/s11069017-3001-5, 2017.

Horner, M. W. and Widener, M. J.: The effects of transportation network failure on people's accessibility to hurricane disaster relief goods: A modeling approach and application to a Florida case study, Nat. Hazards, 59, 1619-1634, 2011.

Lin, C. C., Siebeneck, L. K., Lindell, M. K., Prater, C. S., Wu, H. C., and Huang, S. K.: Evacuees' information sources and reentry decision making in the aftermath of Hurricane Ike, Nat. Hazards, 70, 865-882, 2014.

Lindt, J. W. V. D., Graettinger, A., Gupta, R., Skaggs, T., and Pryor, S.: Performance of Wood-Frame Structures during Hurricane Katrina, J. Perform. Constr. Fac., 21, 108-116, 2007.

Marsooli, R. and Lin, N.: Numerical modeling of historical storm tides and waves and their interactions along the U.S. east 
and Gulf Coasts, J. Geophys. Res.-Oceans, 123, 3844-3874, https://doi.org/10.1029/2017JC013434, 2018.

Montgomery, M. C. and Chakraborty, J.: Assessing the environmental justice consequences of flood risk: a case study in Miami, Florida, Environ. Res. Lett., 10, 095010, https://doi.org/10.1088/1748-9326/10/9/095010, 2015.

USACE: North Atlantic Coast Comprehensive Study: Resilient Adaptation to Increasing Risk, Physical Depth Damage Function Summary Report, United States Army Corps of Engineers, 2015.
Xian, S., Lin, N., and Hatzikyriakou, A.: Storm surge damage to residential areas: a quantitative analysis for Hurricane Sandy in comparison with FEMA flood map, Nat. Hazards, 79, 18671888, 2015.

Xian, S., Lin, N., and Kunreuther, H.: Optimal house elevation for reducing flood-related losses, J. Hydrol., 548, 63-74, 2017. 